\title{
Tensions Arising When Teaching Scientific Disciplinary Core Ideas via Engi- neering Practices (Evaluation)
}

\section{Hannah Smith Brooks, University of Texas at Austin}

Hannah Brooks is a doctoral student at the University of Texas at Austin. Her research focuses on promoting equitable access through collaboration and instructional design. She is also interested in improving teacher education programs in the sciences by studying how teachers plan and structure learning using various methods. She has a BA in Biology and a M.Ed. in middle and secondary instruction from the University of North Carolina at Charlotte. Her interests developed during her time in the science classroom, having worked in both comprehensive and early college high schools. Leadership experiences at the school and county levels challenged her to study how teachers and students interact during learning. She has presented at various national and regional conferences, with work appearing in The Science Teacher and on TeachEngineering.com, and has been awarded a National Endowment for the Humanities grant.

\section{Dr. Todd L. Hutner, University of Texas at Austin}

Assistant Director for Research-Practitioner Partnerships The Center for STEM Education The University of Texas at Austin

\section{Dr. Victor Sampson, University of Texas at Austin}

Associate Professor of STEM Education Director of the Center for STEM Education Department of Curriculum and Instruction

\section{Mr. Lawrence Chu, University of Texas at Austin}

Lawrence Chu is a doctoral student at the University of Texas at Austin studying STEM Education. His research interests include engineering integration in secondary science classes, science assessment development, and educational program evaluation.

\section{Dr. Richard H. Crawford, University of Texas at Austin}

Dr. Richard H. Crawford is a Professor of Mechanical Engineering at The University of Texas at Austin and is the Temple Foundation Endowed Faculty Fellow No. 3. He is also Director of the Design Projects program in Mechanical Engineering. He received his BSME from Louisiana State University in 1982, and his MSME in 1985 and Ph.D. in 1989, both from Purdue University. He teaches mechanical engineering design and geometry modeling for design. Dr. Crawford's research interests span topics in computeraided mechanical design and design theory and methodology. Dr. Crawford is co-founder of the DTEACh program, a "Design Technology" program for K-12, and is active on the faculty of the UTeachEngineering program that seeks to educate teachers of high school engineering.

\section{Dr. Stephanie Rivale, University of Texas at Austin}

Stephanie Rivale is a research faculty member at the Center for STEM Education at the University of Texas. She received her Ph.D. in STEM Education at the University of Texas. She received her B.S. in Chemical Engineering at the University of Rochester and her M.S. in Chemical Engineering at the University of Colorado. She has collaborated on engineering education research with both the VaNTH Engineering Research Center, UTeachEngineering, and the TEAMS Program at the University of Boulder. Dr. Rivale's research uses recent advances in our understanding of how people learn to evaluate and improve student learning in college and K-12 engineering classrooms. Her work also focuses on improving access and equity for women and students of color in STEM fields.

Christina L. Baze, University of Texas at Austin 


\title{
Tensions Arising When Teaching Scientific Disciplinary Core Ideas via Engineering Practices (Evaluation)
}

\begin{abstract}
The Framework for K-12 Science Education calls for engineering practices to be integrated into the teaching and learning of science. We have developed a new instructional model to meet this need, so that teachers are able to develop engineering design tasks that will give students an opportunity to learn how to use engineering practices and the core ideas of science at the same time to develop solutions to meaningful problems. A number of tensions have arisen as we have iteratively designed and tested this new instructional framework in middle school classrooms. In this paper, we identify five specific tensions that arise from (1) attempting to integrate engineering practices and core ideas in non-NGSS states; (2) a need to focus on scientific concepts and engineering practices at the same time; (3) the time required to engaged in engineering practices; (4) different epistemological norms of scientific and engineering communities; and, (5) attempting to balance authenticity and feasibility inside science classrooms. We anticipate that these tensions will arise whenever educators attempt to develop design tasks that integrate engineering practices and core ideas of science for use in science classrooms. While we are unable to provide definitive recommendations for resolving the five tensions prior to beginning a new curriculum or instructional development project, awareness of these potential obstacles will likely ease the challenges associated with the integration of engineering and science in the future projects.
\end{abstract}

\section{Introduction}

The Framework for K-12 Science Education (Framework) aims to elevate engineering practices to a prominent position within science education. The Framework calls for students to learn how to use engineering practices alongside scientific practices to develop solutions to problems because these practices will enable them to better address future societal challenges [1]. In addition to this call, the authors of the Framework also acknowledge that science teachers will need a great deal of support as they learn how to teach in new ways [2]. This support will include, but is not limited to, the development of new instructional materials that will give students opportunities to use engineering practices and the core ideas of science to develop solutions to problems and professional learning experiences for both pre-service and in-service teachers that will enable them to learn how use or create these new instructional materials.

To help address this challenge, our research team have developed a new instructional model called Argument Driven Engineering (ADE) that can be used by science teachers to focus on engineering practices and the core ideas of science at the same time. ADE is designed to give all students an opportunity to learn how to participate in engineering practices within the context of a 6-12 science classroom by integrating authentic and meaningful engineering design into an existing science curriculum. We have also developed four engineering design tasks (EDTs) 
based on this new model that middle school teachers can use without needing to create their own engineering design tasks based on this new model.

As we tested and refined our new instructional model over the last two years, several tensions emerged that we needed to address by making specific trade-offs based on our design criteria and constraints. The purpose of this paper is to outline these tensions, which were identified by both the university-based research team and the classroom teachers who have been collaborating with us on the project, so others can plan for them in the early stages of instructional design. As others educators work to integrate engineering practices into core science courses like we have attempted to do, we anticipate that these tensions will require educators to make trade-offs much as we have done.

In the remainder of this paper, we first review the literature on efforts to integrate engineering into K-12 science courses. We then detail our approach to the development of our instructional framework. Next, we describe the methods used to collect and analyze data from the teachers participating in this study. Fourth, we will identify the five tensions that arose as we tested and refined the ADE framework. Finally, we consider potential implications of these findings for future research and development of new instructional materials.

\section{Literature Review}

While the Framework marks the beginning of a new era in science education reform, particularly with its explicit focus on including engineering design practices as a mechanism for teaching scientific disciplinary core ideas, this is not the first attempt at sweeping, nationwide science education reform. As with prior reform eras (e.g. the alphabet reforms of the 1960s and the Science for All movement of the 1980s and 1990s), we expect tensions will arise as teachers, schools, and districts begin to implement curriculum aligned with the Framework and the Next Generation Science Standards (NGSS) [3, 4]. As an example from the Science for All movement, widespread efforts at increasing the use of inquiry-based instructional practices and fostering students' critical thinking in the classroom illustrated a gap between the intent of science education reformers and the skills and knowledge of science teachers tasked with implementing new instructional approaches. This gap was exacerbated by the lack of teacher preparation programs focusing on these instructional approaches during teacher education coursework, resulting in new teachers struggling to facilitate scientific inquiry $[5,6]$. This teacher preparation tension highlights the importance of providing sustained professional development that educators need to be able to teach in new ways. This is not the only tension to be reported in the literature relevant to nationwide education reform. In this section, we identify additional tensions that arose during previous eras of reform in science education. 
Standards based tensions remain as a major barrier to the integration of engineering practices due to the dynamic nature of education standards and standardized assessment, with classroom teachers and curriculum writers often disagreeing on what should be included $[6,7]$. In the current educational atmosphere, high stakes testing shapes the nature of instruction in many classrooms, as teachers acknowledge it is one of the evaluation tools used to determine growth and success. Often, the pressure for success on high-stakes assessments manifests as rigid pacing structures mandated from district leadership. These top-down mandates often prevent educators from commiting to innovative instructional strategies like project and problem based learning, which have the ability to create a STEM for all environment [8]. As standards change to reflect a greater emphasis of engineering practices, a science or engineering focus tension materializes where teachers may struggle to focus on one discipline instead of relying on integrated instruction.

This tension between integrating two disciplines may be new in engineering education, but has existed for some time for those working to integrate math and science. Following a report by the Carnegie Foundation, which challenged educational systems to improve math and science instruction via integration, several tensions emerged [8]. Experts from several fields, which included mathematicians, scientists, educators, and psychologists, were unable to agree on a definition for the integration of math and science during a three day NSF funded conference [8]. This example highlights one of the struggles that exists for curriculum developers trying to honor two unique epistemologies.

Furthermore, research has suggested that additional barriers exist for science and math integration. Schools are not structured to allow time, space, and materials for effective blended instruction of the two subjects [8]. For many teachers, classroom management concerns arise as teachers struggle to implement integrated instruction requiring hands-on activities and student discourse $[8,5]$. Teachers are often trained in one discipline and receive very little education in additional subject areas, as demonstrated by subject specific licensing requirements in most states [9]. This can lead to scenarios where teachers struggle to find ways to integrate the two subject areas, citing that the content within the two disciplines are incompatible [5]. In addition, many teachers feel that the classroom curriculum is already too crowded, and use that belief to limit extensional activities and content [9].

Finally, Cunningham and Carlsen, suggest that engineering and science practices are inherently different [10]. Engineering design considers trade-offs, an optimal solution to a problem, and focuses on products, while scientific research focuses on identifying and describing underlying processes and constructing explanations for natural phenomenon. In the classroom, engineering promotes systems thinking and discovery through design and evaluation, while science course focus on teaching students established theories and ideas $[10,5]$. Both disciplines, however, use 
questions as guiding factors, require multiple iterations of investigations, and rely on data analysis and interpretation [11]. Researchers and educators should be prepared to balance the scientific content with the engineering design task to effectively reach students, while honoring the epistemic differences between the two fields of study.

\section{Theoretical Underpinnings of the ADE Instructional Framework}

The development of the ADE instructional model is grounded in social constructivist theories of learning, considering that students learn through social interactions and repeated personal practice $[12,6]$. Students benefit from the social interactions through exposure to new concepts, language, representations, and practices that make science and engineering unique disciplines. In order for these social interactions to be productive in terms of learning, students must interact with people who are familiar with the norms and epistemological commitments within each field. Our team drew upon the expertise of engineers, engineering educators, science educators, and middle school science teachers to craft design based tasks that fostered the goals of both the engineering and scientific communities.

The ADE instructional model rests on three postulates about student learning. First, learners should have multiple opportunities to integrate and use disciplinary core ideas, crosscutting concepts, engineering practices, and literacy skills to develop solutions to real world problems using engineering and science concepts. Second, students should have opportunities to discover scientific and mathematical principles required in design and provide evidence-based feedback using these ideas. Third, students must learn the value of reflection and feedback as a way to improve a solution and the process by which they arrive at the solution, including how they design, test, and share potential ideas. As students move through the learning process, they are able to develop an understanding of what makes certain practices more productive and provide the reasoning to support their argument. When students are provided the opportunity to engage in these practices and receive feedback from peers, they are able to model the norms and expectations of both epistemological communities.

The ADE instructional framework is based on Argument Driven Inquiry (ADI), a instructional model that centers on student engagement in scientific inquiry. Research on ADI suggests that students using the ADI model in science show gains in content knowledge, writing and communication skills, research design abilities, and capacity to argue from evidence [13-15]. Building the ADE framework using previous ADI work allowed the integration of engineering practices emphasized in the Framework into an evidence-based instructional framework. ADE also promotes a truly iterative cycle for student design, where participants have multiple opportunities to interact with content and engage with scientific and engineering practices leading to potential for learning [1]. 
The ADE model aims to include engineering and science content and practices in learning activities while considering equitable opportunities for each student in the class. It supports classroom assessments that are closely aligned with NGSS standards, while promoting student engagement in critical thinking, oral and written discourse, and informed decision making [16]. It draws on Cunningham and Carlsen's work indicating that using evidence to build need-to-know connections for students through science, engineering design tasks can increase student motivation to understand scientific principles $[10,11]$. The ADE instructional model includes the following components: problem identification; concept generation; concept evaluation and selection; an iterative design-test-revise process; and a written report that undergoes a peer review process [17].

In developing this new framework, we chose to focus on middle school students, as this provides early access to the engineering design process for all students. As misperceptions of the nature of engineering, low academic self-esteem, and poor self-efficacy can influence student career choice, both for female students and culturally and linguistically diverse students from ethnic groups underrepresented in the engineering profession, providing students with positive experiences in engineering design within the academic setting may serve as a catalyst for future course selection and career pathways [18-20].

\section{Method}

We now detail the steps we took to develop and implement the ADE instructional framework and the associated data collection that occurred concurrently with these steps. First, we detail the steps we took to develop the framework and the four associated EDTs during the 2016-2017 academic year. We then detail the steps we took during the first phase of classroom implementation during the 2017-2018 academic year.

\section{IV.a. Development of the Instructional Framework}

In the Fall of 2016, the research team used the ADE instructional framework to design four EDT modules organized around existing middle school science standards. The team utilized the NGSS engineering-based performance expectation standards for endothermic and exothermic reactions, heat transfer, biodiversity, and Newton's Laws of motion. respectively, as guidelines for building the classroom design challenges. Teacher participation in developing the modules was critical, so that they were willing to attempt the change in instructional practice [21]. A one-day design institute occured in March 2017, where the university research team worked alongside teachers and district representatives to model a design task to develop a passive vaccine storage device, requiring students to understand the properties of heat transfer. The participants were asked to provide feedback on the additional three EDT topics, observations 
which led the research team to remove a previously designed EDT and replace it with a design task on biodiversity. The four EDTs were completed in April 2017.

In May 2017, the four EDTs were piloted at one of the two participating middle schools. One member of the research team piloted each EDT in one class. During the pilot, at least one other member of the research team observed and took notes on both strengths of each EDT and areas of needed improvement. The classroom teachers were also asked to provide feedback on the specific EDTs and the overall instructional framework.

Finally, to prepare the seven teachers to implement the EDTs during the 2017-2018 academic year, and to address Cunningham and Carlsen's concern regarding the role of iterative, reflective teacher professional development, the team lead a week-long teacher workshop in June 2017 [10]. During this week long seminar, teachers from the two participating middle schools modeled and prepared for classroom EDT facilitation.

\section{IV.b. Classroom Testing}

The EDTs were implemented in 8th grade science classrooms during the 2017-2018 school year. The team included 8th grade science teachers working at two middle schools in the same district in a suburban area of central Texas. Hill Valley Middle School (HVMS) is comprised of 1500 students, with $18.5 \%$ classified by the state as Hispanic and $4.6 \%$ classified as African-American. DeLorean Middle School (DLMS) is made up of 1100 students, of whom $42 \%$ classified by the state as Hispanic and $12.5 \%$ classified as African-American.

The first EDT was implemented in September, and focused on heat transfer. Students were tasked to design a passive vaccine storage container. EDT two was implemented in October, with students designing a hand-warmer that could be stored and distributed to homeless individuals if and when needed. EDT three was implemented in November and December, and asks students to develop a pit-trap device for studying biodiversity and ecosystem health. EDT four was implemented during January and February, with students designing a crash barrier to reduce the force acting on a moving cart. Each implementation was monitored by university researchers, and provided valuable feedback for the overall ADE framework and EDT modules.

Data collection included video recording of group meetings with HVMS and DLMS teachers, and interviews with participating teachers following the implementation of each EDT. The interview process incorporated targeted questions specific to teacher background, knowledge of engineering education and the effectiveness of the EDT module. The interviews with teachers occured after major project milestones--after the week long professional development and after each unit was taught during the school year. Following the completion of the first EDT, 
participating teachers were asked about the role that engineering practices played in their current planning process. Similarly, teachers were asked to identify tensions that future teachers might face if they decide to design and integrate engineering tasks following the second EDT. After the third EDT, teachers were asked to list pros and cons for using the EDTs within the science classroom. Teacher interviews, utilizing pseudonyms to protect anonymity, were transcribed and coded for further analysis. Tensions were identified relating to teachers, researchers, or both based on the group most impacted. Teacher tensions included time and science or engineering focus, researcher tensions originated from feasibility and authenticity challenges and epistemological differences between the disciplines. Both groups identified standards alignment as a significant tension arising from the work to integrate engineering practices into an existing science curriculum.

\section{Findings}

As mentioned above, the purpose of this paper is to identify tensions that arise during the design of an instructional framework and materials that aim to teach scientific disciplinary core ideas through engineering practices. During the development and implementation process of the ADE framework in two area schools alongside middle school science educators, we became aware of five tensions that complicated this process. Tensions were identified through teacher interviews, interactions with district personnel, feedback collected from teacher professional development, and observations collected during the implementation of each EDT. Based on our data, we suggest that a tension surrounding standards alignment exists, as some states include engineering design in state standards but others do not. Tension between focusing on science or engineering practices, while considering the allotment of time for both also emerged. Finally, tensions surrounding the epistemological differences within each discipline and the relationship between authenticity and feasibility were identified as challenges to future projects aimed at increasing engineering education.

\section{V.a. Standards Alignment Tensions}

Many states have not adopted the NGSS, leaving the majority of teachers to rely on state specific standards that may or may not integrate engineering practices into science curriculum [22]. As illustrated through an interview with Ms. Baines (September 21, 2017), teachers may want to integrate more engineering skills into science instruction, but feel as though they do not fit into the scripted standards provided by the state. Said Ms. Baines:

"I really want to be incorporating engineering into things that I'm doing because I can see what a future need it's going to be. I think that it will make my students more competitive in the world. It's just unfortunate that the place that I live does not have those learning standards embedded into them" 
As the research team designed the four model EDTs, they confronted the challenge associated with focusing on disciplinary core ideas found in the NGSS with state science standards that lack any emphasis on engineering practices.

There are 27 state standards for 8th grade science in Texas, with a heavy emphasis on Earth and Physical Science. Only four of the standards relate to Life Science, the topic of a proposed EDT module in which students were instructed to create a weather proof air-quality monitoring device. While this design task met the NGSS requirement of addressing the relationship between air-quality and biodiversity, it was too far removed from the state standards for 8 th grade science. In states where engineering is not directly supported in the science standards, it can be very challenging to craft learning activities that meet the learning goal completely, while providing students an opportunity to learn and practice design based thinking.

During the implementation of the four EDT modules in area schools, the university based research team was questioned through emails sent by local district administration regarding EDT alignment to state standards. While many classroom teachers support increasing engineering practices in the classroom, the district leadership requires a very clear relationship between the science content presented through the EDT and the state science standards. Ms. Baines calls attention to this dilemma, "Because it's not represented in our standards, it's hard to get ... I think it's going to be hard to get by them. Not by teachers but by people who tell teachers what to do." With strict district guidelines regarding content and instruction, classroom teachers worry about evaluation and assessment based on the student outcomes on standardized tests.

\section{V.b. Science or Engineering Focus Tensions}

Supporters of science education reform have suggested narrowing the content covered in standards so that students are able to deeply explore the most important concepts, yet the NGSS expands the content by adding crosscutting concepts and engineering practices through three dimensional instruction. When working to integrate engineering into science education, a tendency to prioritize one discipline over the other occurs. In the early stages of the ADE instructional framework, we placed emphasis on the engineering practices embedded in the EDT with limited consideration of the scientific content supporting the investigation. During the piloting phase, students evaluated designs based on cost and size constraints without considering the scientific principles governing the transfer of heat into the vaccine. Based on this discovery, the instructional framework was modified, with more time and emphasis on scientific disciplinary core ideas (DCI). Unfortunately, this change led students to tinker instead of systematically solve the problem. One teacher, for example, remarked, "because they were thinking building and not really the other stuff" (Ms. Clayton, September 21, 2017). 
A balance between scientific principles and engineering practices is an important aspect to consider when designing and implementing engineering curricula. Based on the observations gathered from our participant teachers, they want to incorporate engineering into science instruction. Ms. Clayton sees a natural relationship between the two fields, both scientific investigation and engineering provide a solution to a natural problem. Using this model provides students with an improved learning experience, hopefully leading to increased recognition and application of the important concepts and skills involved in the activity completion. The science or engineering focus may be a tension to carefully consider, but teachers, such as Ms. Clayton, want a chance to try using real world scenarios to help students discover science.

\section{V.c.Time for Engineering Tensions}

Time is a precious commodity in the classroom, so naturally it surfaced as one of the largest obstacles to integrating engineering practices into the science curriculum. As Ms. Parker indicated during an interview, "I am two days behind the district, which is not bad" (September 19, 2017). Our EDT modules were designed to provide students space to move through the design process while focusing on a DCI, meaning that completing one EDT took more time than an inquiry-based science lab for the same concept. While teachers repeatedly expressed this tension as an obstacle to implementation, Ms. Parker also acknowledged that the EDTs, "went deeper into science, which only benefits them" (September 19, 2017).

At the start of this project (March 2017), the middle school science teachers were informed that the EDTs would take between 250-300 minutes each. Following revisions to the instructional framework to address the science or engineering focus tension, the time required increased to 500 minutes. Unfortunately, this increase in time meant that some of the EDT was not discussed

or completed with fidelity as outlined by Ms. Baines in a follow up interview, "There was a good couple of sheets, at least, in the packet that, at least my students, we didn't have time to get to." (September 21, 2017). The research team shares the concern about the amount of time required to provide opportunities for students to learn and practice engineering in an authentic setting.

\section{V.d. Epistemological Tensions}

While closely related, science and engineering are two distinct disciplines with unique norms and epistemological commitments. Within the engineering community, designs are analyzed on the basis of criteria and constraints. Engineers are required to consider trade-offs, and judge designs based on the value gained or lost through these compromises. Therefore designs can be judged differently based on the value assigned by the evaluator [23]. Furthermore, engineering design often leads to proprietary impact [11]. In contrast, there is free exchange of information and no value judgements for the explanation of natural phenomena within the scientific community. 
When students are asked to draw on the epistemological commitments of the scientific community while learning about engineering practices, it can lead to confusion about when to use each discipline. According to Mr. McFly, students are asked to evaluate designs from different perspectives, but they lack confidence in their own understanding of design, "they weren't super confident in their own designs" (September 19, 2017), leading to difficulty in the ability to critique or analyze the work of their peers.

One challenge to teaching students the subtle differences in the scientific and engineering communities is a lack of teacher understanding. If we expect teachers to integrate engineering practices into the science classroom, then teachers need to be educated on how to teach both [11]. As we worked with our teacher participants, Ms. Parker indicated that they work very hard to understand material before leading classroom instruction, so that they are able to answer questions and anticipate potential issues. However, Mr. McFly also felt unprepared to lead instruction on engineering because he struggled to understand the nature of engineering. Ms. Parker leans towards the mathematical approaches to engineering or the artistic use of drawing and materials, without addressing the systematic approach used by engineers to solve problems. Even without the integration of engineering, there are vast differences in the way science teachers think about and teach about the nature of scientific inquiry [7]. This issues creates a unique challenge for those working to educate students on the epistemological communities within the scientific and engineering disciplines [24].

\section{V.e. Authenticity and Feasibility Tensions}

Current research suggests that introducing relevant, authentic problems in the classroom increases student engagement in the learning process. When students are more committed to the task, they develop a deeper understanding of the scientific principles involved in solving the problem . Burgin and Salder, for example, point out that student investigations "are most impactful when they are highly authentic in terms of their similarities to the actual workings of Science, Technology, Engineering and Math (STEM) professionals [25]." The challenge remains to craft learning opportunities that are authentic, yet still accessible to students and feasible to complete in the classroom.

Considering the impact of authenticity on student outcomes, the EDTs aimed to provide students with experiences solving problems similar to those that a practicing engineer might face. During the course of our work developing and implementing the EDTs an inverse relationship surfaced, where problem authenticity often decreased as classroom feasibility increased. Truly authentic problems tend to require more resources that may be scarce or unavailable to classroom teachers. Our teachers indicated that materials would be hard to afford, and would require a significant amount of preparation time before classroom implementation of a large module. Ms. Baines 
states cost concerns for teachers absent the external support provided by the research project "would be very overwhelming and it might be enough to make somebody hesitate to even get started" (September 21, 2017). This issue may act as a barrier for classroom implementation.

When we adjusted the curricula to include easily accessible equipment and materials, we found that problems became artificial or oversimplified. Using an example from our work, we proposed an EDT in which students were asked to evaluate competing design solutions for maintaining biodiversity and ecosystem services. This task allowed for many authentic problems ranging from protecting coastal communities from hurricanes to proposing a clean up strategy for the Great Pacific garbage patch. In both of these scenarios, the prototype testing phase would require proximity to water. This presents a feasibility problem for most schools, because even if they are located near a large body of water many districts have strict policies against allowing students access to water. We revised the task so that students were able to test prototypes in stream tables, but this reduced the authenticity of the design task. In addition, safety concerns emerged as another barrier to authentic testing and prototype building. Ms. Parker suggested that allowing students items such as box cutters as a component of the building process might lead others to remove materials or test phases from the project, she says "I mean, I just kinda of depends on what type of worry wart you are" (September 19, 2017). By limiting the resources available to students to increase the classroom feasibility, the authenticity of the engineering skill decreases. The ongoing struggle between creating authentic problems for students to address within the science classroom, an environment with its own needs and constraints, is an important component to consider when designing new instructional approaches or materials.

\section{Discussion}

Educational reform is challenging. The process of reform requires extensive time and effort to elicit even a small shift in thinking and subsequent instructional practice as evidenced by the resistance shown through the push to integrate math and science in the past. The Framework and the NGSS require integration of engineering practices into science classrooms, so educators and researchers should expect to experience similar resistance.

Given the benefit of increasing scientific literacy and an understanding of the engineering design process, we anticipate that curriculum developers and educators will work to develop novel approaches to blend the two disciplines together. As engineering education becomes situated within science instruction, natural tensions will become apparent. It is our hope that the tensions identified in this paper will provide insight into the design of engineering tasks for educators and researchers to consider during the production of future learning activities. 
These tensions may be applicable beyond the context of science, as others consider adding engineering practices to courses. We hope that future work on engineering education can build on the tensions we discovered in our experiences with science teachers. While there are significant tensions regarding the alignment of learning activities to state standards that are not the NGSS or based on the Framework, some classroom science teachers, like Ms. Clayton, will want to help students develop problem solving abilities, and see a direct relationship between engineering practices and critical thinking. Building on teachers desire to promote those skills in students will increase teacher and student engagement in the learning process, an idea supported by Ms. Baines. An introductory engineering module, that does not need to be directly aligned to any particular standard, allows teachers to practice effective facilitation and students to engage with relevant science content in a meaningful way. This strong connection between disciplines can improve understanding for students [8].

During periods of reform, both for science inquiry and subject area integration, time is often identified as an obstacle to effective implementation of new programs or approaches [5,9]. In our participating classrooms, limited time for module completion resulted from time needed for building and testing. Even with the challenge associated with allocating enough time to fit the engineering design tasks into the existing district curriculum pacing guide, Ms. Parker acknowledged that students engaged in the process and did not focus on the time spent completing the design tasks in the same way that they track time during other instructional activities. Furthermore, providing teachers time during the summer to learn and model the design based modules proved a beneficial use of time for both researchers and classroom teachers. Ms. Baines and Mr. McFly indicated that summer planning provided the science teachers with protected time to think about and process the new content. While not a solution to the ever present challenge of finding time, providing time for professional development outside of the district school day provided a creative way to allow teachers to participate in the inquiry and reflect on the process, two critical components to successful integration $[5,9]$.

The tension to focus more on engineering or science was one faced by the research team designing the EDT modules, but classroom teachers saw this balance as a relevant way to teach problem solving. They suggest that it allowed students a chance to empathize and relate learning to real life scenarios, a belief closely aligned with the goals outlined in previous literature suggesting a math/science integration model [8]. This meaningful nature of the learning is believed to increase student retention of material, a theme throughout our teacher interviews and supported by research on subject area connections [8]. In addition, the epistemological tension between the two disciplines calls for future research on the impact these differences may have on classroom design and implementation. We suggest that future studies should look at how students may authentically engage in the epistemological communities for engineering and other disciplines currently taught in the public school system. 
Finally, we uncovered an interesting relationship between the authenticity of the design task and the classroom feasibility. Crawford [4], for example, suggests that students will struggle to complete scientific inquiry in the classroom because they lack the necessary expertise and are confronted with different goals than those of the scientific community, with students learning existing knowledge and scientists working to develop new knowledge. The challenge to provide students with authentic experiences, while still promoting development of scientific knowledge, should be considered by curriculum developers working to integrate disciplines such as engineering and computer science into pre-existing courses. Furthermore, careful consideration for the feasibility of integrated tasks completed in classrooms can support classroom teachers in implementation. Curriculum developers and educators should anticipate possible responses to emerging tensions as they work to help students access new skill sets and content.

The tensions we outline will occur naturally in the public school classroom. We anticipate that they will continue to serve as an obstacle to the integration of innovative instruction in the classroom. While we do not have specific suggestions to mitigate these tensions, due to external constraints placed on our research, it is important to be aware of how they may influence the adoption or effectiveness of new engineering programs. The resolution of the tensions outlined in this paper will rely on a team of district personnel, classroom teachers, researchers, and curriculum developers working together to produce innovative solutions. 
References

[1] National Research Council, A Framework for K-12 Science Education: Practices, Crosscutting Concepts, and Core Ideas. Washington, D.C.:The National Academies Press, 2012.

[2] NGSS Lead States, Next Generation Science Standards: For States, By States. Washington, DC: The National Academies Press, 2013.

[3] J.L. Rudolph, Scientists in the Classroom: The Cold War Reconstruction of American Science Education. New York: Palgrave, 2002.

[4] National Academies of Sciences, Engineering, and Medicine, Board on Science Education and Teacher Advisory Council, Division of Behavioral and Social Science and Education, Science Teachers Learning: Enhancing Opportunities, Creating Supportive Contexts. Committee on Strengthening Science Education through a Teacher Learning Continuum, Washington, DC: The National Academies Press, 2015.

[5] B.A. Crawford, "From inquiry to scientific practices in the science classroom," in Handbook of Research in Science Education, N. Lederman \& S.K. Abell, 2nd ed., New York, N.Y.: Routledge, 2014, pp. 515-541.

[6] R. Duschl, "Science education in three-part harmony: Balancing conceptual, epistemic, and social learning goals," Review of Research in Education, vol. 32, issue 1, pp. 268-291, 2008.

[7] M.G. Jones, \& M. Leagon, "Science teacher attitudes and beliefs: Reforming practice," in Handbook of Research in Science Education, N. Lederman \& S.K. Abell, 2nd ed., New York, N.Y.: Routledge, 2014, pp. 830-847.

[8] C.M. Czerniak, \& C.C. Johnson, "Interdisciplinary science teaching," in Handbook of Research in Science Education, N. Lederman \& S.K. Abell, 2nd ed., New York, N.Y.: Routledge, 2014, pp. 395-411.

[9] J.W. McBride, \& F.L. Silverman, "Integrating elementary/middle school science and mathematics," School Science and Mathematics, vol. 91, issue 7, pp. 285-292, 1991. 
[10] C.M. Cunningham \& W.S. Carlsen, "Teaching engineering practices," Journal of Science Teacher Education, vol. 25, issue 2, pp. 197-210, 2014.

[11] C.M. Cunningham, \& W.S Carlsen, "Precollege engineering education," in Handbook of Research in Science Education, N. Lederman \& S.K. Abell, 2nd ed., New York, N.Y.: Routledge, 2014, pp. 747-758

[12] C. Anderson, "Perspectives on science learning," in Handbook of Research in Science Education, N. Lederman \& S.K. Abell, 1st ed. Mahwah, N.J.: Lawrence Erlbaum Associates, 2007, pp. 3-30.

[13] V. Sampson, J. Grooms, \& J. Walker. "Argument-driven inquiry as a way to help students learn how to participate in scientific argumentation and craft written arguments: An exploratory study," Science Education, vol. 95, issue 2, pp. 217-257, March, 2011.

[14] V. Sampson, P. Enderle, J. Grooms \& S. Witte, "Writing to learn by learning to write During the school science laboratory: Helping middle and high school students develop argumentative writing skills as they learn core ideas," Science Education, vol. 97, issue 5, pp. 643-670, September, 2013.

[15] J.P. Walker, \& V. Sampson, "Learning to argue and arguing to learn: Argument-driven inquiry as a way to help undergraduate chemistry students learn how to construct arguments and engage in argumentation during a laboratory course," Journal of Research in Science Teaching, volume 50, issue 5, pp. 561-596. May, 2013.

[16] T.J. Moore, M.S. Stohlmann, H.H. Wang, K.M. Tank, \& G.H. Roehrig, "Implementation and integration of engineering in K-12 STEM education," in Engineering in Pre-College Settings: Synthesizing Research, Policy, and Practices. S. Purzer, J. Strobel, \& M. Cardella, Eds., West Lafayette, IN: Purdue University Press, 2014.

[17] C. Baze, T.L. Hutner, L. Chu, V. Sampson, R. Crawford, S. D. Rivale, H. S. Brooks, "An instructional framework for the integration of engineering into middle school science classrooms," in NSF Grantees Poster Session: Proceedings of the ASEE Annual Conference, Salt Lake City, UT, USA, June 24-27, 2018, In press.

[18] C. Buchmann, T.A. DiPrete, and A. McDaniel. "Gender inequalities in education," Annual Review of Sociology. vol. 34, pp. 319-337, April, 2008. 
[19] National Academy of Engineering, Committee on Public Understanding of Engineering Messages, Changing the Conversation: Messages for Improving Public Understanding of Engineering, National Academies Press, 2008.

[20] S.M. Lord, M.M. Camacho, R.A. Layton, R.A. Long, M.W. Ohland, and M.H. Washburn. "Who's persisting in engineering? A comparative analysis of female and male asian, black, hispanic, native american, and white students," Journal of Women and Minorities in Science and Engineering, vol. 15: pp. 167-190, 2009.

[21] R. Lazarowitz, "High school biology curricula development: Implementation, teaching, and evaluation from the 20th to the 21st century," in Handbook of Research in Science Education, N. Lederman \& S.K. Abell, 2nd ed., New York, N.Y.: Routledge, 2014, pp. 412-433.

[22] National Science Teachers Association, About the Next Generation Science Standards. August, 2017.

[23] Lead States, "Engineering design in the NGSS," Washington, D.C.: National Academies Press.

[24] J. Osborne, "Scientific practices and inquiry in the science classroom," in Handbook of Research in Science Education, N. Lederman \& S.K. Abell, 2nd ed., New York, N.Y.: Routledge, 2014, pp. 579-599.

[25] S.R. Burgin, \& T.D. Sadler, "Learning nature of science concepts through a research apprenticeship program: A comparative study of three approaches," Journal of Research in Science Teaching, vol. 53, issue 1, pp. 31-59, January, 2016. 

